\title{
Cytotoxic and Proliferative T Cell Responses in HIV-1-infected Macaca nemestrina
}

\author{
Stephen J. Kent, * Lawrence Corey, ${ }^{\star \star \$}$ Michael B. Agy, ${ }^{\S \mid}$ William R. Morton," M. Julianna McElrath, * \\ and Philip D. Greenberg*1 \\ Departments of * Medicine, ${ }^{\ddagger}$ Laboratory Medicine, ${ }^{8}$ Microbiology, $"$ the Regional Primate Research Center, and ${ }^{~ I m m u n o l o g y, ~}$ \\ University of Washington, Seattle, Washington 98195
}

\begin{abstract}
Macaca nemstrina has been described as an animal model for acute HIV-1 infection. This animal, unlike most infected humans, appears to contain HIV-1 replication. Therefore analysis of HIV-1-specific proliferative and cytotoxic $T$ lymphocyte (CTL) responses following HIV-1 challenge of $M$. nemestrina may provide information into the role of such responses in both the control of acute HIV infection and protective immunity. Although $\mathrm{CD4}^{+} \mathrm{T}$ cell responses to HIV-1 are generally difficult to detect in HIV-1-infected humans, early and persistent $\mathrm{CD4}^{+} \mathrm{T}$ cell proliferative responses to HIV-1 antigens were detected in all HIV-1-inoculated $M$. nemestrina. HIV-1-specific $\mathrm{CD8}^{+} \mathrm{CTL}$ responses were evaluated in PBMC by stimulation with autologous cells expressing HIV-1 genes, limiting dilution precursor frequency analysis, and T cell cloning. CTL reactive with gag, env, and nef were present 4-8 wk after infection, and persisted to 140 wk after infection. The presence of both $\mathrm{CD4}^{+}$and $\mathrm{CD8}^{+} \mathrm{T}$ cell responses before and after clearance of HIV-1 viremia is consistent with a role for these responses in the successful control of HIV-1 viral replication observed in $M$. nemestrina. Further studies of $T$ cell immunity in these animals that resist disease should provide insights into the immunobiology of HIV-1 infection. (J. Clin. Invest. 1995. 95:248-256.) Key words: HIV-1 • T lymphocytes • cytotoxic - T4 lymphocytes - Macaca nemestrina
\end{abstract}

\section{Introduction}

The pig-tailed macaque, Macaca nemestrina (M. nemestrina), has recently been described as an animal model of acute HIV1 infection $(1,2)$. Intravenous inoculation of several strains of HIV-1 has resulted in a clinical rash and lymphadenopathy syndrome 2-12 wk after inoculation and a transient viremia lasting 4-24 wk. Long-term HIV-1 replication is restricted,

This work was presented in part at the Keystone Symposium on AIDS Pathogenesis conference March 1993 and Conference on AIDS Vaccine Development October 1993.

Address correspondence to Stephen J. Kent, AIDS Pathogenesis Research Unit, Macfarlane Burnet Centre for Medical Research, PO Box 254, Fairfield, Victoria, Australia 3078. Phone: 61-3-2802823; FAX: 61-3-2802561.

Received for publication 8 February 1994 and in revised from 28 July 1994

J. Clin. Invest.

(c) The American Society for Clinical Investigation, Inc. 0021-9738/95/01/0248/09 \$2.00

Volume 95, January 1995, 248-256 however, despite detection of persistent HIV-1 DNA in PBL and splenic lymphocytes. The cause of this inhibition in viral replication is unclear, but may be due at least in part to immunologic containment of HIV-1 replication. Antibodies to multiple HIV-1 proteins, including neutralizing antibodies to HIV-1 envelope, have been detected in HIV-1-infected $M$. nemestrina $(1,2)$ but to date no studies of cellular immune responses have been reported.

Cellular immune responses are critical for either the elimination or immunologic control of most viral infections and may be necessary components of a successful vaccination program to induce protection against viral challenge (3). In HIV-1infected humans, $\mathrm{CD} 4^{+} \mathrm{T}$ cell proliferative responses to HIV1 proteins are rarely present, even early in infection, and this apparent lack of CD4 cell responsiveness to HIV-1 may play a role in both the failure to generate and maintain an immune response effective at controlling HIV-1 and the etiology of the subsequent immunodeficiency (4). $\mathrm{CD}^{+}$cytotoxic $\mathrm{T}$ lymphocytes (CTL), specific to multiple HIV-1 proteins are readily detectable in HIV-1-infected humans, and correlative studies as well as analysis of viral escape variants suggest that such effector cells play a role in control of the infection $(5,6)$.

CD4- and CD8-mediated T cell responses have also been detected in recipients of candidate HIV-1 and simian immunodeficiency virus vaccines, although the definitive role of $\mathrm{T}$ cell immune responses in protective immunity to HIV-1 and SIV remains to be defined (7-10). Analysis of cellular immune responses in HIV-1-infected macaques, a host that appears to contain viral replication, should facilitate further definition of the parameters of protective immune responses to HIV-1. As such, we measured $\mathrm{T}$ lymphocyte proliferative and cytotoxic responses in PBMC from HIV-1-infected M. nemestrina. Our data indicate that both CD8-mediated cytotoxic and CD4-mediated proliferative $\mathrm{T}$ cell responses to HIV-1 proteins are present early and persist for $>100 \mathrm{wk}$ in HIV-1-infected $M$. nemestrina. Moreover, limiting dilution cultures can be used to both isolate HIV-1-specific CTL clones and quantify the frequency of CTL precursors. These responses in HIV-1-infected M. nemestrina provide insights into the role of cellular immunity in resistance to HIV-1 disease in these primates.

\section{Methods}

Cell lines. B lymphoblastoid cell lines (BLCL) were established from each macaque by infecting $10^{5}$ freshly isolated PBMC in $100 \mu$ l of

1. Abbreviations used in this paper: APC, antigen-presenting cells; BLCL, B lymphoblastoid cell lines; CTL, cytotoxic T lymphocytes; CTLp, cytotoxic L lymphocyte precursors; CRA, $51 \mathrm{Cr}$ release assay; $\mathrm{rVV}$, recombinant vaccinia viruses; SIV, simian immunodeficiency virus. 
R15 (RPMI 1640 supplemented with L-glutamine penicillin $100 \mathrm{U} / \mathrm{ml}$, streptomycin $100 \mu \mathrm{g} / \mathrm{ml}$, and 15\% FCS [Whittaker M. A. Bioproducts, Inc., Walkersville, MD]) with $100 \mu$ l of supernatant from S394-1X1055 cells (a kind donation of Dr. Sharp, Southwest Foundation for Biomedical Research, San Antonio, TX) containing Herpes virus papio, a baboon herpesvirus, in a 96-well, U-bottomed plate (Costar Corp., Cambridge, MA). African green monkey kidney cells (BSC-40), maintained in DME supplemented $10 \%$ FCS, were used to generate stocks of vaccinia viruses.

$T$ cell proliferative responses. Freshly separated PBMC were incubated in quadruplicate replicate cultures at $10^{5}$ cells per well in 96-well U-bottomed plates for $6 \mathrm{~d}$ with $10 \mu \mathrm{g} / \mathrm{ml}$ preparations of HIV-1 antigens, including psoralen-inactivated whole HIV- $1_{\mathrm{LAI}}$ and HIV-1 $1_{\mathrm{SF} 2}$, and recombinant HIV-1 $1_{\mathrm{SF} 2}$ gp120 produced in Chinese hamster ovary cells (kindly provided by Dr. K. Higgins, Chiron, Emeryville, CA), in a total of $200 \mu$ l. PBMC were incubated with media alone to assess unstimulated control responses, and stimulated with PHA (Sigma Chemical Co. St. Louis, MO, $10 \mu \mathrm{g} / \mathrm{ml}$ ) and Candida antigen (Casta, Greer Labs, Lenoir, NC, $20 \mu \mathrm{g} / \mathrm{ml}$ ) as positive mitogenic and antigenic control responses. Wells were pulsed with $2.5 \mu \mathrm{Ci}$ of $\left[{ }^{3} \mathrm{H}\right]$ thymidine (NEN Products, Boston, MA) $18 \mathrm{~h}$ before harvesting with a cell harvester (Cambridge Technology, Inc., Watertown, MA). Proliferation is expressed as stimulation index (mean $\left[{ }^{3} \mathrm{H}\right]$ thymidine incorporation of cells stimulated with antigen/mean incorporation in absence of stimulation).

Recombinant vaccinia viruses ( $r V V$ ). The entire gag and env genes of HIV-1 $1_{\text {LAI }}$ were inserted into wild type vaccinia (New York City Board of Health strain) as previously described $(11,12)$ (kindly donated by S.-L. Hu, Bristol Meyers, Squibb, Seattle, WA). The entire $n$ ef gene of HIV- $1_{\text {LAI }}$ was inserted into wild type vaccinia, as previously described (13) (vTFnef, kindly donated by S. Koenig, MedImmune, Inc., Gaithersburg, MD). The rVV were amplified and titered on BSC-40 cells.

In vitro generation of CTL. CTL activity in PBMC was assessed in vitro by sequential bulk stimulation cycles as a modification of previously described methods (14). For cycle 1, freshly isolated PBMC for use as stimulators were infected with rVV, expressing either gag, env, or $n e f$ at a an moi of 10 for $90 \mathrm{~min}$ in $200 \mu \mathrm{l}$ of R10 (similar to $\mathrm{R} 15$, except $10 \%$ human serum pooled from screened volunteers was used instead of FCS), washed twice, and placed $4 \mathrm{~cm}$ from an ultraviolet light source for $10 \mathrm{~min}$; the stimulator cells were incubated with freshly isolated PBMC cells at a ratio of 10 responder : 1 stimulator cell at $37^{\circ} \mathrm{C}$ in $5 \% \mathrm{CO}_{2}$ for $7 \mathrm{~d}$ at $10^{6}$ cells $/ \mathrm{ml}$. Cycle 2 and subsequent weekly stimulators were prepared using autologous BLCL infected with rVV at an moi of 10 for $16 \mathrm{~h}$, and inactivated with an ultraviolet light source and $\gamma$-irradiation $(8,000 \mathrm{rad})$. These stimulator cells were added to the responder population at a ratio of 10 responder : 1 stimulator cell. Freshly isolated autologous $\gamma$-irradiated (3,000 rad) PBMC filler cells were also added at a ratio of 1 responder : 1 filler cell to the culture. Each well, containing $10^{6}$ responder cells in R10 media, was supplemented 2 d after stimulations with $2 \mathrm{U} / \mathrm{ml}$ of rIL-2 (Hoffman-La Roche, Nutley, NJ).

Assay for cytolytic activity. Cytolytic activity was measured in a standard 4- $\mathrm{h}{ }^{51} \mathrm{Cr}$ release assay (CRA). Autologous BLCL targets were infected with an rVV at an moi of 10 , labeled with $0.1 \mu \mathrm{Ci} \mathrm{Na}{ }^{51} \mathrm{CrO}_{4}$ (NEN Products) for $16 \mathrm{~h}$, gently washed three times with HBSS (Whittaker M. A. Bioproducts, Inc.) with $2 \%$ FCS, resuspended in R10, and plated at $5 \times 10^{3}$ BLCL targets per well in U-bottomed 96-well plates (Costar Corp.). Effector cells were washed and added to targets at varying E/T ratios to a total volume of $200 \mu \mathrm{l}$. After a 4-h incubation $100 \mu \mathrm{l}$ of each well was sampled and counted (Beckman Instrs., Inc., Fullerton, CA; $\gamma-5,500 \mathrm{~B}$ ). Spontaneous release was determined by harvesting supernatant from targets cultured in media only and maximum release from targets lysed with $1 \%$ NP-40 detergent, and percent specific release calculated by standard formula. Standard deviation of replicate wells was always less than $10 \%$ and spontaneous release was always less than $30 \%$ of the maximal release.

Analysis of lymphocyte subpopulations. Phenotypic analysis of cells present in bulk stimulated cultures of PBMC was determined by twocolor flow cytometry with either FITC or phycoerythrin (PE)-conju- gated mAbs directed against CD8 (Leu-2a-PE) and CD4 (Leu-3aFITC). The $\mathrm{T}$ cell lineage of $\mathrm{CD}^{+}{ }^{+}$and $\mathrm{CD} 8{ }^{+}$populations being studies was demonstrated by two-color flow cytometry using a second $\mathrm{mAb}$ to CD3 (Leu-4-PE or FITC, all from Becton Dickinson, Mountain View, CA).

To subsequently determine the specific subset of cells present in PBMC cultures mediating the observed proliferative and cytolytic responses, subpopulations were isolated before assay by adherence to a 25- $\mathrm{cm}^{2}$ flask coated with an $\alpha \mathrm{CD} 8 \mathrm{mAb}$ (A.I.S., Menlo Park, CA) for $1 \mathrm{~h}$. The nonadherent population (CD4 ${ }^{+}$-enriched cells) was aspirated, and the adherent population ( $\mathrm{CD}{ }^{+}$-enriched cells) subsequently gently removed with a cell scraper (Costar Corp.). The relative enrichment of $\mathrm{CD}^{+}$and $\mathrm{CD}^{+}{ }^{+} \mathrm{T}$ cells achieved by these methods was determined by analyzing each population using two-color flow cytometry following staining with CD4-FITC and CD8-PE mAbs as described above.

Cloning of CTL to HIV-1 gag. Cloning of T cells was performed as a modification of previously described methods (15). Briefly, following generation of bulk-stimulated PBMC cultures containing HIV-1 gagspecific cytolytic activity, cells from these cultures were plated at 1 effector cell per well in 96-well U-bottomed plates (Costar Corp.) Each well was stimulated with $10^{4}$ vac-gag-infected autologous BLCL (ultraviolet, and $\gamma$-irradiated), $10^{5}$ autologous PBMC filler ( $\gamma$-irradiated), and rIL-2 $100 \mathrm{U} / \mathrm{ml}$. Wells in which growth was present were expanded by specific antigen restimulation as described above, tested for cytolytic activity, and analyzed for phenotype by flow cytometry with $\mathrm{mAbs}$ to $\mathrm{CD} 8, \mathrm{CD} 4, \mathrm{CD} 3$ (as described above), and CD16 (Leu11a-FITC, Becton Dickinson).

Limiting dilution analysis of cytotoxic $T$ lymphocyte precursor (CTLp) frequencies. Analysis of $\mathrm{CTL}_{\mathrm{p}}$ frequencies in the PBMC of macaques to HIV-1 gag was performed by a modification of previously described methods (16). Briefly, fresh PBMC were plated in 96-well plates at dilutions of $8 \times 10^{5}-5 \times 10^{4}$ cells/well in 24 replicates. Each well was stimulated with $10^{4}$ vac-gag-infected autologous BLCL (ultraviolet- and $\gamma$-irradiated) and supplemented with $25 \mathrm{U} / \mathrm{ml} \mathrm{rIL-2} \mathrm{every}$ $3 \mathrm{~d}$ to ensure that adequate helper function was present without the requirement for helper cells. After $10 \mathrm{~d}$ of culture, cells in each well were divided and assayed for cytolytic activity against a panel of three BLCL targets. The targets expressed either no antigens other than those derived from the $H$. papio virus used to transform the B cells (uninfected BLCL), vaccinia virus antigens (vaccinia-infected BLCL), or HIV-1 gag antigen (vac-gag-infected BLCL). Wells were considered positive against a particular target if cytolysis exceeded by three standard deviations the mean spontaneous release from 24 replicates of the target cultured in media alone. $\mathrm{CTL}_{\mathrm{p}}$ frequencies and confidence intervals were determined by the statistical method of $\chi^{2}$ minimization and assumes a single hit model and Poisson distribution as described by Taswell (17). Data was expressed on a log scale as proportion of negative wells and graphed against cells/well.

Analysis of macaques infected with HIV-1. All animals were housed in stainless steel containment cages in a BSL-3 facility at the University of Washington Regional Primate Research Center, and anesthetized with ketamine $(10 \mathrm{mg} / \mathrm{kg}$ i.m.) before blood draws. Eight HIV-1-infected and four uninfected control $M$. nemestrina were studied. Animals F89111, F89115, T92051, J92076, 93086, and 93089 were infected with cell-associated and cell-free stocks of HIV-1 $1_{\text {LAI }}$, animal $J 90402$ was infected with cell-free HIV-1 $1_{\text {LAI }}$, animal M74046 was infected with cellfree and autologously infected lymphocytes from a previously described

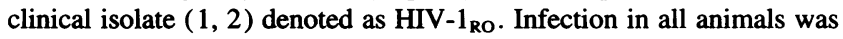
confirmed by assay for anti-HIV antibodies by a whole virus EIA (Genetic Systems, Redmond, WA), virus isolation by co-culture with PHAstimulated donor human PBMC, and PCR of PBMC DNA using the HIV-1 gag-specific primers $S K 38 / 39(1,2)$. All eight animals were healthy and had normal CD4 and CD8 lymphocyte counts, with no change in the CD4/CD8 ratio, at all time points evaluated after infection.

\section{Results}

Proliferative responses. PBMC proliferative responses were measured as an initial reflection of $\mathrm{T}$ cell recognition of HIV- 
1 proteins. PBMC from infected or control uninfected animals were stimulated with either whole inactivated HIV-1 virus, purified gp 120, Candida Ag, or PHA. None of three control uninfected animals proliferated to the HIV-1 antigens (stimulation index $<1.7$ ), but did respond to PHA (stimulation index $>20$ ) and Candida $\mathrm{Ag}$ ( stimulation index $>5$ ). All five infected animals studied demonstrated significant proliferative responses (stimulation index $>5$ ) to two strains of whole inactivated HIV-1 (LAI and SF2) and to recombinant gp120, as well as to PHA and Candida. Each of the five animals was evaluated at a minimum of three distinct time points after infection, and proliferative responses to HIV-1 antigens were detected on every assay. Responses were present at the first time points measured (three animals evaluated at 4 wk postinfection) and persisted in two animals that were monitored as far as $140 \mathrm{wk}$ postinfection. Representative lymphoproliferative assays to HIV-1 antigens from two uninfected control animals and two infected animals, one assayed early and one late postinfection, are shown in Fig. $1 A$.

$\mathrm{CD}^{+}{ }^{+} \mathrm{T}$ cells are the predominant cells responsible for the proliferative response to HIV-1 in humans $(4,18,19)$, and we evaluated the relative role of $\mathrm{T}$ cell subsets in the proliferative response to HIV-1 in infected $M$. nemestrina. PBMC from animal F89115 were separated into CD8-enriched and CD4-enriched populations by panning on an $\alpha \mathrm{CD} 8 \mathrm{mAb}$-coated flask and tested as above. Enrichment for $\mathrm{CD}^{+}$and $\mathrm{CD} 4{ }^{+}$cell populations was confirmed by FACS analysis. Of the adherent cells removed from the $\alpha \mathrm{CD} 8$-coated flask, 88-94\% expressed CD8, and $2-6 \%$ of this CD8-enriched population expressed CD4. The CD4-enriched population, represented by the cells nonadherent to the flask, contained $67-82 \% \mathrm{CD}^{+}$cells, as compared to $35-45 \%$ in the unfractionated PBMC. The CD4-enriched population demonstrated a stronger proliferative response to HIV-1 than the unfractionated population, whereas the CD8enriched population demonstrated a substantially lower response than the unfractionated population. These results suggest that $\mathrm{CD}^{+} \mathrm{T}$ cells were the predominant cell responding by proliferation (Fig. $1 B$ ).

HIV-l gag-specific cytolytic activity in bulk-stimulated cultures. HIV-1-specific CTL have been detected in humans in fresh PBMC and in PBMC stimulated with autologous cells infected with rVV-expressing HIV-1 genes (5). Fresh PBMC were evaluated in all eight HIV-1-infected $M$. nemestrina, and no direct HIV-1 - specific lytic activity was detected. We therefore adapted a method that we had previously reported to improve the sensitivity of detection of virus-specific CTL (14, 20 ), in which the responder cells are stimulated for sequential cycles with cells expressing HIV-1 antigen. The initial stimulation was performed with autologous rVV-infected PBMC as stimulators. At weekly intervals thereafter, the cells were harvested and restimulated with rVV-infected autologous BLCL (Note: autologous H. papio-transformed BLCL were not used for the initial stimulation to avoid enrichment of $\mathrm{T}$ cells potentially reactive with $H$. papio products ). $2 \mathrm{~d}$ after the second and subsequent stimulations, $2 \mathrm{U} / \mathrm{ml} \mathrm{rIL-2}$ were added to cultures to supplement helper function for $\mathrm{CD}^{+}$responses.

Specific cytolytic activity ( $\%$ specific lysis $>10 \%$ ) to HIV$1 \mathrm{gag}$ from bulk-stimulated PBMC cultures was detected in four of five HIV-1-infected $M$. nemestrina following three to five sequential stimulations, but was not detected in PBMC cultures from three uninfected control $M$. nemestrina stimulated in an identical manner (five or more experiments from each

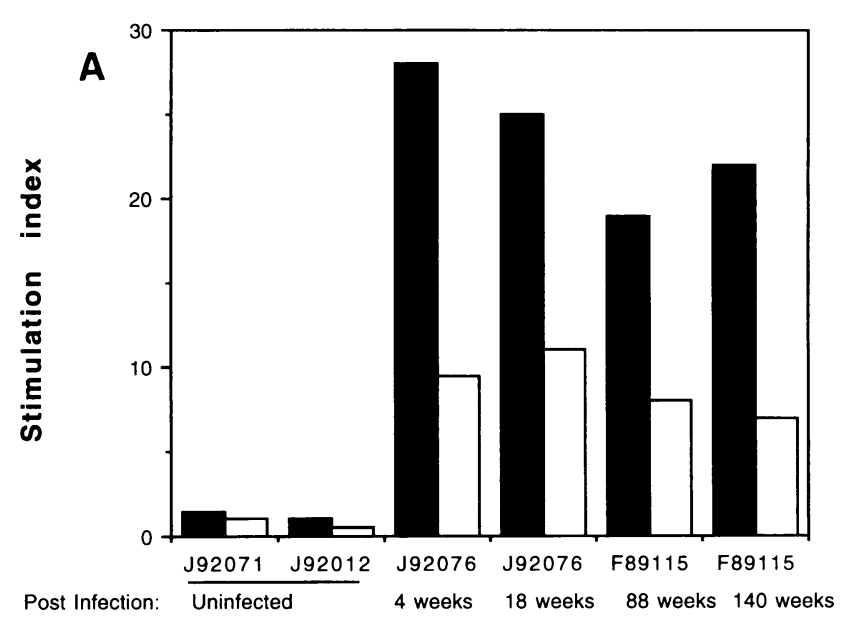

Animal No. at time post infection

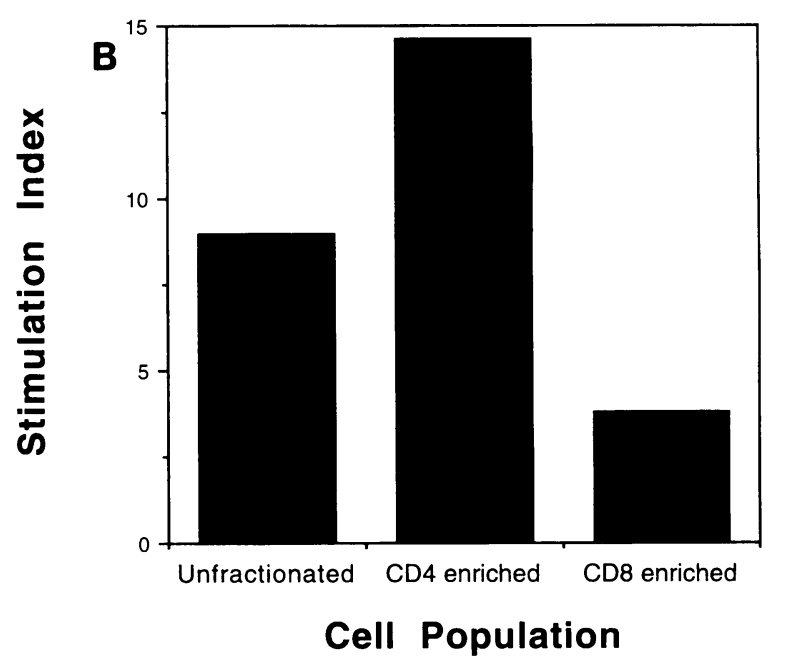

Figure 1. (A) The proliferation of PBMC from M. nemestrina on exposure to whole inactivated HIV-1 or gp120. Fresh PBMC from either uninfected control $M$. nemestrina or HIV-1-infected $M$. nemestrina were incubated for $7 \mathrm{~d}$ with either whole psoralen-inactivated HIV-1 ${ }_{\mathrm{SF} 2}$ (a) or recombinant HIV-1 $1_{\text {SF2 }}$ gp $120(\square)$ at $10 \mu \mathrm{g} / \mathrm{ml}$ and $\left[{ }^{3} \mathrm{H}\right]$ thymidine incorporation measured. Animals F89115 (88-140 wk after infection) and J92076 ( $4 \mathrm{wk}$ after infection) were infected with HIV-1 $1_{L_{A I}}$ and animals J9207I and J92012 were uninfected controls. ( $B$ ) Determination of the cell subset mediating proliferative response in HIV- $1_{\text {L.AI }}$-infected $M$. nemestrina animal F89115 ( $120 \mathrm{wk}$ after infection). Cells were separated into CD8- or CD4-enriched populations using an $\alpha$-CD8 mAbcoated flask and proliferation to whole psoralen-inactivated HIV-1 $1_{\mathrm{SF} 2}$ at $10 \mu \mathrm{g} / \mathrm{ml}$ was measured after $7 \mathrm{~d}$ by $\left[{ }^{3} \mathrm{H}\right]$ thymidine incorporation.

animal). Background lysis of vaccinia-infected or uninfected BLCL was always less than $6 \%$. Representative experiments from two infected animals (Fig. 2, $A$ and $B$ ) and one control animal (Fig. $2 C$ ) are shown. HIV-1 gag-specific lysis was detected at two or more separate time points in four of five HIV1 -infected animals (Table I). The animal with no discernable response was tested only on one occasion. One animal (T92051) was assayed for HIV-1 gag-specific lysis before and 

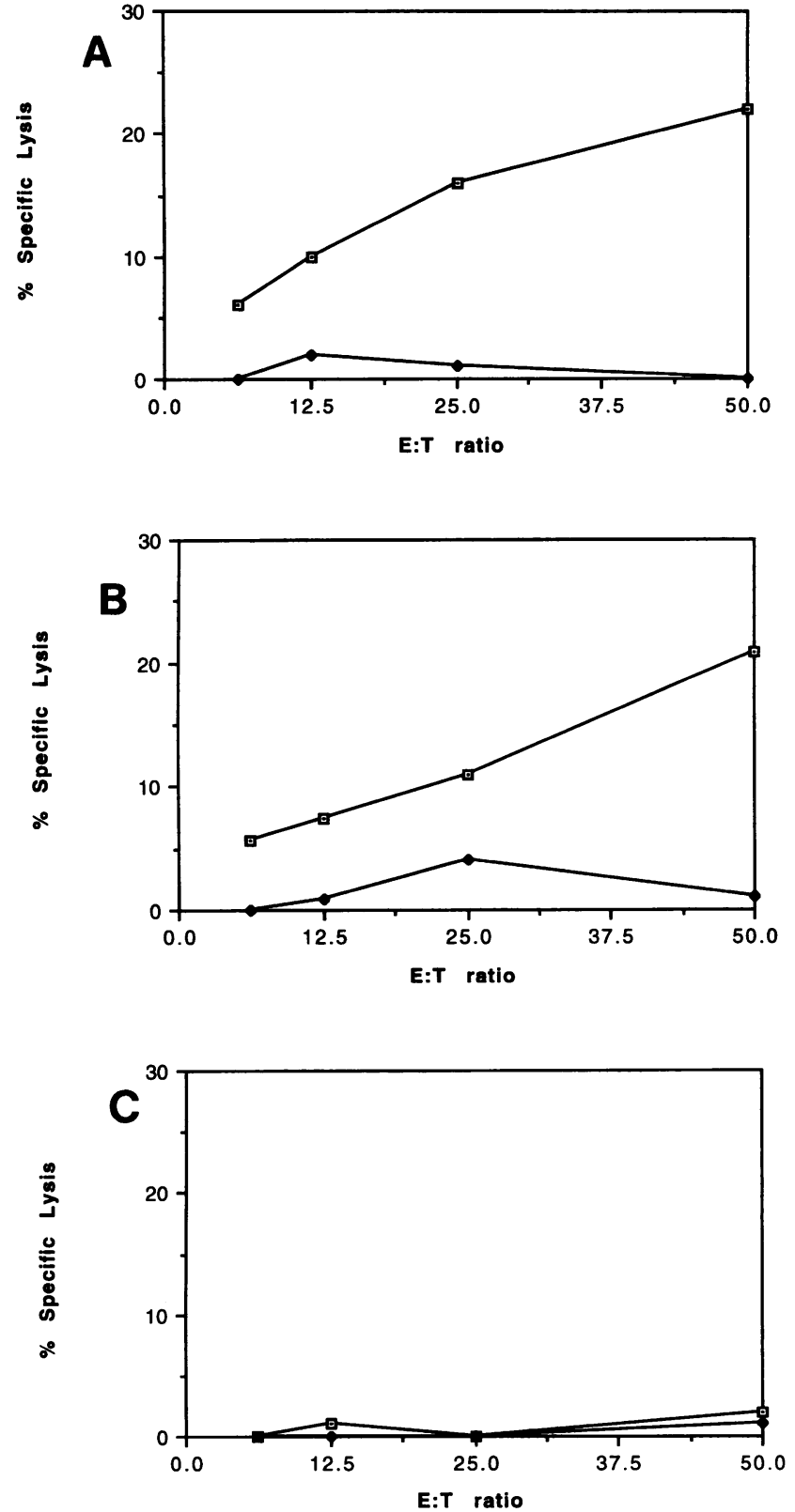

Figure 2. Lysis of vac-gag-infected autologous BLCL by antigenstimulated PBMC from $M$. nemestrina. PBMC which underwent 3-5 sequential stimulations, initially with.autologous vac-gag-infected PBMC and subsequently with autologous vac-gag-infected $\gamma$-irradiated BLCL and autologous filler, were tested in a standard 4-h CRA against vac (•)- or vac-gag (๑)-infected autologous ${ }^{51} \mathrm{Cr}$-labeled BLCL targets. Representative experiments are shown from two HIV-1 infected animals ( $A$, animal F89111 and $B$, animal M74046) and a control uninfected animal $(C)$.

after inoculation with HIV-1, and specific lysis was only detected after infection (Table I).

Persistence of HIV-1 gag-specific CTL. HIV-1 gag-specific CTL activity was evaluated at several time points following infection in four animals to determine the durability of responses (Table I). Persistent gag-specific CTL activity in animals F89111 and M74046 was detected from bulk-stimulated PBMC cultures assayed as described on five occasions from 80 to 140
Table I. HIV-I gag-specific CTL in HIV-1-infected Macaques

\begin{tabular}{|c|c|c|c|c|c|c|c|}
\hline \multirow[b]{2}{*}{ Animal No. } & \multirow{2}{*}{$\begin{array}{c}\text { Target } \\
\text { cell } \\
\text { infection* }\end{array}$} & \multicolumn{6}{|c|}{ Percent specific lysis at time after infection } \\
\hline & & $\begin{array}{l}-2 \\
\mathrm{wk}\end{array}$ & $\begin{array}{c}4 \\
\mathrm{wk}\end{array}$ & $\begin{array}{c}12-20 \\
\text { wk }\end{array}$ & $\begin{array}{c}52- \\
80 \mathrm{wk}\end{array}$ & $\begin{array}{l}112 \\
\mathrm{wk}\end{array}$ & $\begin{array}{l}140 \\
w k\end{array}$ \\
\hline T92051 & vac & $0^{\ddagger}$ & 0 & 0 & - & - & - \\
\hline (infected) & vac-gag & 0 & 11 & 10 & - & - & - \\
\hline M74046 & vac & - & 1 & 3 & 2 & - & - \\
\hline (infected) & vac-gag & - & 21 & 11 & 17 & - & - \\
\hline F89111 $1^{\S}$ & vac & - & - & - & 0 & 1 & 0 \\
\hline (infected) & vac-gag & - & - & - & 22 & 10 & 10 \\
\hline F89115 & vac & - & - & - & 3 & 3 & 1 \\
\hline \multirow[t]{3}{*}{ (infected) } & vac-gag & - & - & - & 12 & 7 & 14 \\
\hline & & \multicolumn{6}{|c|}{ Percent specific lysis at time after initial monitoring } \\
\hline & & $\begin{array}{c}0 \\
\text { wk }\end{array}$ & $\begin{array}{c}4 \\
\mathrm{wk}\end{array}$ & $\begin{array}{c}10-12 \\
\text { wk }\end{array}$ & $\begin{array}{c}16- \\
18 \mathrm{wk}\end{array}$ & $\begin{array}{c}24-28 \\
w k\end{array}$ & $\begin{array}{c}42-54 \\
\text { wk }\end{array}$ \\
\hline $86092^{\|}$ & vac & 3 & 0 & 2 & 2 & 1 & 0 \\
\hline (uninfected) & vac-gag & 0 & 0 & 1 & 2 & 1 & 2 \\
\hline $89218^{\|}$ & vac & 0 & 0 & 0 & 4 & 0 & 0 \\
\hline (uninfected) & vac-gag & 1 & 0 & 0 & 1 & 0 & 0 \\
\hline
\end{tabular}

* Target cells were vac and vac-gag-infected autologous ${ }^{51} \mathrm{Cr}$-labeled BLCL. ${ }^{\ddagger}$ Percent specific lysis by Ag-specific stimulated cultures of HIV-1 inoculated $M$. nemestrina PBMC at three time points at E/T ratios of 50:1. - , not tested. Infected animals were each analyzed at three separate time points, as presented. ${ }^{\S}$ PBMC from animals F89111 and F89115 were unavailable for study before $80 \mathrm{wk}$ after infection. " PBMC of uninfected animals were tested on multiple occasions in an identical manner to the infected animals.

wk after infection and 4-52 wk after infection, respectively. Animal F89115 demonstrated gag-specific CTL activity at weeks 92 and 140 after infection, but not at week 112 after infection and animal T92051 showed gag-specific CTL at weeks 4 and 12 after infection, but not before infection or at week 8 after infection.

Effector $T$ cell population mediating cytolytic activity to $H I V-1$ gag. Four bulk-stimulated cultures of PBMCs from HIV1 -infected $M$. nemestrina containing gag-specific cytolytic activity were evaluated by flow cytometric analysis. A mean of $93 \%$ of cells were $\mathrm{CD}^{+}$(range 91-96\%), 66\% were $\mathrm{CD}^{+} \mathrm{CD}^{+}$(range $54-74 \%$ ) and a smaller subset of $20 \%$ were $\mathrm{CD} 4{ }^{+} \mathrm{CD}^{+}$( range $14-32 \%$ ). FACS analysis confirmed that $>96 \%$ of $\mathrm{CD}^{+}$of $\mathrm{CD}^{+}{ }^{+}$cells were $\mathrm{CD}^{+}$. The predominance of cells expressing CD8 in these cultures suggested that this population might be responsible for the observed cytolytic activity, but a significant participation by the $\mathrm{CD} 4{ }^{+}$subset could not be excluded. $\mathrm{CD}^{+}$cells were therefore purified from the bulk-stimulated PBMC cultures by panning on an $\alpha \mathrm{CD} 8$ monoclonal antibody-coated flask. To determine the efficiency of this panning method for enriching $\mathrm{CD} 8^{+}$cells from macaques, the cells were analyzed on a FACS. The adherent population was $94 \% \mathrm{CD}^{+}$, whereas the nonadherent population was largely depleted of $\mathrm{CD}^{+}$cells, containing only $4 \% \mathrm{CD}^{+}$cells. Bulk-stimulated PBMC cultures that were separated into CD8enriched and CD8-depleted populations were assessed for HIV1 gag-specific lytic activity (Fig. 3), and the CD8-enriched population contained nearly all of the detectable lytic activity. 


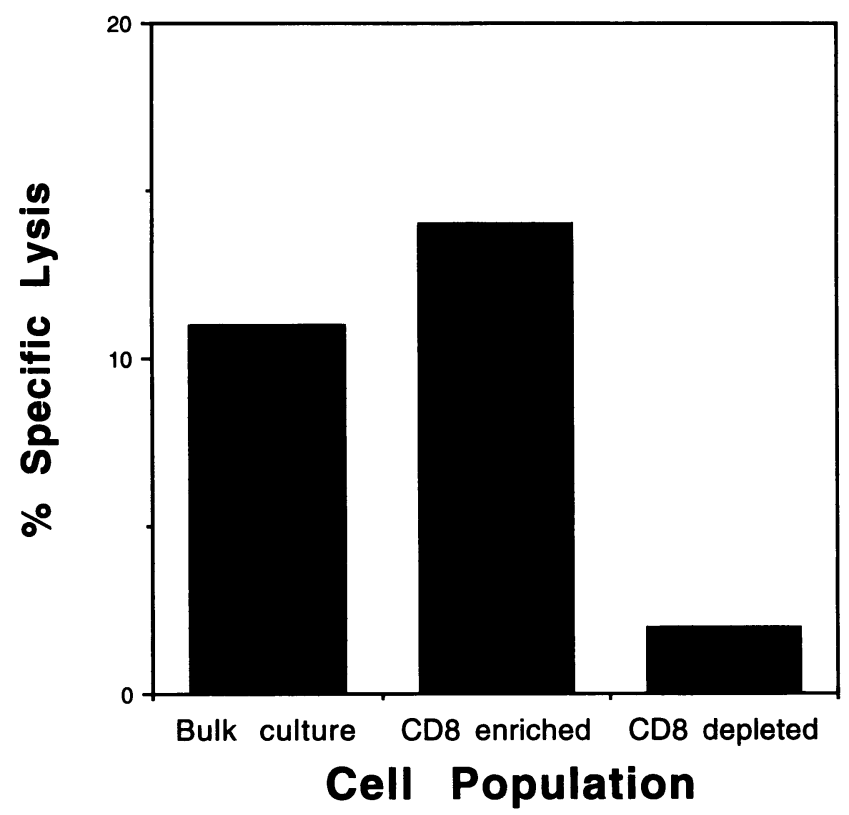

Figure 3. Determination of the cell subset mediating CTL response to HIV-1 gag in HIV-1-infected M. nemestrina animal M74046. Cells from a bulk culture containing HIV-1 gag-specific lysis were separated into CD8-enriched or CD8-depleted populations using an $\alpha$-CD8 mAbcoated flask and lysis of autologous vac-gag-infected ${ }^{51} \mathrm{Cr}$-labeled BLCL determined in a standard 4-h CRA. The E/T ratio was 25:1.

HIV-1 env- and nef -specific cytolytic activity in bulk-stimulated cultures. To assess CTL responses to HIV-1 proteins other than gag, PBMC were also examined by similar methods for the presence of $e n v$-and $n e f$-specific CTL. Specific lytic activity (lysis $>10 \%$ ) to env was detected in two of four HIV-1infected M. nemestrina. Animal M74046 was evaluated three times and animal F89111 was evaluated twice, and both animals had $e n v$-specific lysis detectable at each occasion tested, as described below. At an E/T ratio of 50:1, the lytic activity from animal M74046 for targets infected with vac-env was $12 \%$ at $8 \mathrm{wk}$ after infection, $11 \%$ at $40 \mathrm{wk}$ after infection and $14 \%$ at 52 wk after infection, with background vaccinia lysis of $4 \%$, $2 \%$, and 3\%, respectively. Animal F89111 had lytic activity at an E/T ratio of 50:1 for vac-env targets of $16 \%$ at $100 \mathrm{wk}$ after infection and $10 \%$ at 132 wk after infection, with background vaccinia lysis of 7 and $0 \%$, respectively. Two animals, T92051 and F89115, tested on a single occasion each, failed to demonstrate $e n v$-specific lytic activity. Two uninfected control animals were evaluated on three separate occasions, and neither animal ever demonstrated greater than $2 \%$ env-specific cytolytic activity following stimulation in an identical manner.

Env-specific CTL in HIV-1-infected humans has been reported to be mediated by both $\mathrm{CD} 4{ }^{+}$and $\mathrm{CD} 8^{+}$cells $(21)$, and we therefore sought to determine whether CD4 ${ }^{+}$CTL contributed significantly to the lytic activity detected in HIV-1-infected macaques. Bulk-stimulated PBMC, obtained from animal M74046 at 52 wk after infection, were separated into $\mathrm{CD}^{+}{ }^{+}$ and $\mathrm{CD} 4^{+}$-enriched populations, as described in Methods, and assayed for $e n v$-specific lytic activity. The unfractionated population exhibited $14 \%$ env-specific lytic activity at an E/T ratio of 50:1, the CD8-enriched population exhibited $19 \%$ env-specific lysis, and the CD4-enriched population exhibited $4 \%$ env-spe- cific lytic activity. Lysis of vaccinia-infected control targets was $<4 \%$ in all populations. Thus, the majority of the lytic activity to env was mediated by $\mathrm{CD}^{+}$cells, with little contribution from $\mathrm{CD}^{+}{ }^{+}$cells.

Nef-specific CTL have been reported to be of potential importance in clearance of HIV-1 in humans $(22,23)$, and we therefore examined the infected macaques for the presence of $n e f$-specific CTL. Two macaques were evaluated at $8 \mathrm{wk}$ after infection. Bulk-stimulated PMBC cultures of animal 93089 exhibited $13 \%$ lysis of vac- $n$ ef-infected autologous BLCL versus $2 \%$ lysis of vaccinia-infected autologous BLCL at an E/T of 25:1. Animal 93086 exhibited weaker lytic activity towards $n e f$, with $7 \%$ lysis of vac- $n$ ef targets and $2 \%$ lysis of vac targets at an $\mathrm{E} / \mathrm{T}$ of $25: 1$. By contrast, two uninfected animals had less than $1 \%$ lysis of $n$ ef-expressing targets.

Estimation of frequency of HIV-1 gag CTLp. Gag-specific CTL in HIV-1-infected $M$. nemestrina was not present in fresh PBMC, as has been described in humans, but rather required several in vitro stimulations for detection. This suggested that gag-specific CTL precursors might be present in frequencies relatively lower than those in humans who have chronic viremia. Therefore, the frequency of gag-specific CTLp was determined by limiting dilution culture. PBMC were plated at limiting dilutions and stimulated for $10 \mathrm{~d}$ with autologous vac- $g a g$-infected BLCL in wells supplemented with $25 \mathrm{U} / \mathrm{ml} \mathrm{rIL-2,} \mathrm{and} \mathrm{the} \mathrm{re-}$ sponding cells were tested against autologous BLCL targets expressing vac-gag. Frequencies of CTLp specific for gag were estimated in two HIV-1 -infected animals and two control uninfected animals at two time points (Fig. 4). The relative frequency in animal M74046, infected with both cell-free and cellassociated HIV-1, was estimated at 1/327,000 (95\% confidence interval [CI] $1 / 249,000-1 / 476,000)$ at $24 \mathrm{wk}$ after infection (Fig. $4 A$ ) and $1 / 380,000(95 \%$ CI 1/290,000-1/536,000) at 32 wk after infection. Animal J90402, infected with only cellfree HIV-1, was tested at $42 \mathrm{wk}$ after infection (Fig. $4 \mathrm{~B}$ ), with the gag-specific CTLp frequency estimated as $1 / 134,000$ cells (95\% CI $1 / 101,000-1 / 199,000)$, and at $52 \mathrm{wk}$ after infection, with the frequency estimated at $1 / 170,000$ cells (95\% CI $1 /$ 130,000-1/246,000). The CTLp frequency to targets infected with vaccinia alone (range: $1 / 1,300,000-1 / 2,600,000$ in four experiments ) or uninfected BLCL targets (range: $1 / 1,900,000-$ $1 / 4,900,000)$ was significantly lower in the two infected animals. The CTLp to vac-gag-infected targets from two control uninfected $M$. nemestrina in four experiments each were lower than in infected animals (range: $1 / 1,700,000-1 / 3,700,000$, and had similar CTLp frequencies as the HIV-infected animals to vaccinia or uninfected targets (range: 1/2,300,000-1/ 13,000,000).

Generation of an HIV-1 gag-specific CTL clone. Analysis of HIV-1-specific CTL responses in primates would be facilitated by the availability of $\mathrm{CD}^{+} \mathrm{T}$ cell clones. To determine if HIV-specific $\mathrm{CD} 8^{+} \mathrm{T}$ cell clones could be isolated and expanded, cells from a bulk-stimulated culture of PBMC from macaque M74046 which contained gag-specific CTL activity were plated at 1 cell/well and stimulated with vac-gag-infected BLCL, autologous irradiated PBMC as filler cells, and rIL-2 as described in Methods. Cell growth was observed in 6 of 960 wells plated, and cells from these wells were expanded and tested for cytolytic activity. Cells derived from one of these six positive wells demonstrated HIV-1 gag-specific lysis following screening against vac- and vac- $g a g$-infected targets. Cells from this well were expanded by repetitive cycles of specific stimula- 

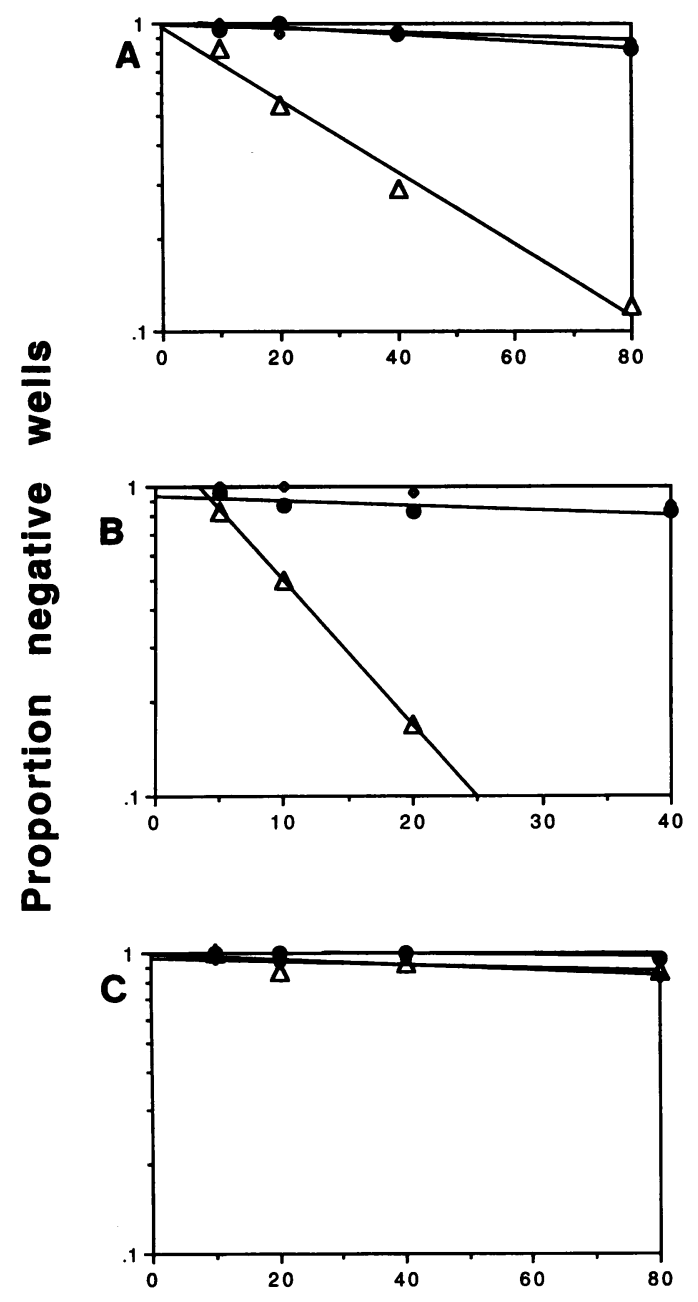

Cells/well $\times 10^{4}$

Figure 4. CTLp frequencies of HIV-1 gag-specific CTL were estimated by limiting dilutional analysis. Fresh PBMC were plated in increasing dilutions of 24 replicates ranging from $5 \times 10^{4}$ to $80 \times 10^{4}$ cells/well and stimulated with autologous vac-gag-infected BLCL and $25 \mathrm{U} / \mathrm{ml}$ rIL-2. Cells from each well were harvested after $10 \mathrm{~d}$ and split for assay of cytolytic activity against multiple targets. Targets used were ${ }^{51} \mathrm{Cr}$ labeled mock infected autologous BLCL $(\bullet)$, vaccinia-infected autologous BLCL $(\diamond)$ or vac-gag-infected autologous BLCL $(\Delta)$. Wells were considered positive if cytolytic activity exceeded that spontaneous release by 3 SD. Representative experiments on two HIV-1-infected animals ( $A$, animal M74046 and $B$, animal J90402) and an uninfected animal $(C)$ are shown.

tion with cells expressing gag plus supplemental IL-2. Following expansion, the cell population demonstrated $60 \%$ specific lysis of HIV-1 gag at an E/T ratio of 10:1 (Fig. 5). By FACS analysis, the cells derived from this single well were $99 \%$ $\mathrm{CD}^{+} 4^{-} 8^{+} 16^{-}$. A control uninfected animal had no clonal growth when stimulated in an identical manner.

Definitive evidence that the gag-reactive cells from this well were clonal would require reagents for directly analyzing $T$ cell receptor gene rearrangements in macaques, which are not available. However, the likelihood that this reactive cell population is clonal can be calculated by relative probabilities of plating and detecting reactivity from more than one cell. Assuming

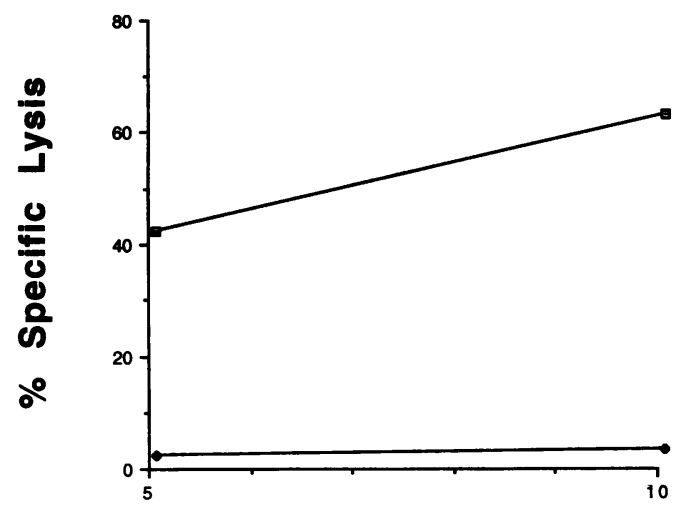

E:T ratio

Figure 5. Cells from a bulk culture of PBMC from animal M74046 in which HIV-1 gag-specific CTL were present were cloned in limiting dilution by stimulating with autologous vac-gag-infected BLCL, autologous filler, and rIL-2. Wells which contained cell growth were expanded and tested for cytolytic activity against vac ( $\bullet)$ - or vac-gag (घ) -infected autologous ${ }^{51} \mathrm{Cr}$-labeled BLCL targets.

a Poisson distribution, the probability that one or more cells is plated in a well when plated from a suspension diluted to 1 cell $/ 100 \mu \mathrm{l}$ is 0.63 (Minitab Statistics for MS-DOS). Therefore, of the 960 wells plated, $(960 \times 0.63)$ or 605 wells are likely to have contained at least one cell. Of the wells that contained at least one cell, the probability that $\geq 2$ cells were added to a well when plated at this dilution is 0.41 . Since only $1 / 605$ of the wells plated that contained cells demonstrated growth and was reactive for HIV-1 gag, the likelihood that the well exhibiting the gag-specific cytolytic activity reflected the outgrowth of two or more cells is $(0.41 \times 1 / 605)$, or $1 / 1,475$. Thus, the probability that this population is derived from a single cell and thus is clonal is $>99.9 \%$.

\section{Discussion}

Our study is the first to demonstrate HIV-1-specific proliferative and cytotoxic T cell responses in HIV-1-infected M. nemestrina. T cell proliferative responses to HIV-1 envelope protein and inactivated HIV-1 were readily detectable in all animals tested at time points from 4 to 140 wk postinfection. These HIV-1-specific proliferative responses were predominantly mediated by $\mathrm{CD}^{+}{ }^{+} \mathrm{T}$ cells. Cytotoxic $\mathrm{T}$ cell responses to HIV-1 were detected to HIV-1 env, gag, and nef proteins. CTL responses were present from 4 to $140 \mathrm{wk}$ after infection, were mediated by $\mathrm{CD}^{+} \mathrm{T}$ cells, and were seen in animals inoculated with both cell-associated and cell-free HIV-1.

Persistent $\mathrm{CD}^{+}{ }^{+} \mathrm{T}$ cell proliferative responses were observed in all animals to HIV-1 $1_{\text {LAI }}$ (the infecting strain in four of the five animals), the antigenically related SF-2 strain, and purified recombinant gp120. The stimulation indices to these HIV-1 antigens were similar or greater than that observed to SIV in macaques vaccinated with SIV envelope preparations, and to HIV-1 in chimpanzees and humans vaccinated with various HIV-1 envelope preparations (24-26) but, unlike the response to those vaccine preparations, did not appear to decline over time. The persistence of $\mathrm{CD} 4{ }^{+} \mathrm{T}$ cell responses has been reported in experimental systems to require the persistence of stimulating antigen, typically on antigen-presenting cells such 
as follicular dendritic cells (27). However, this does not necessarily require the persistence of replicating virus. For example, we have previously reported that $\mathrm{CD}^{+} \mathrm{T}$ cell responses to vaccinia virus persist for $>15 \mathrm{yr}$ after immunization (28), despite the fact that this virus has no demonstrable latency in the host. Thus, immunization with or exposure to viable viruses may more efficiently provide antigen reservoirs for maintaining $\mathrm{CD}^{+}{ }^{+}$memory responses.

Humans infected with HIV-1 typically demonstrate poor proliferative responses to HIV-1, even at early time points when the host is asymptomatic and the number of $\mathrm{CD}^{+}$cells is normal $(4,19)$. In distinction to these findings, the macaques infected with HIV-1 demonstrated strong and persistent proliferative responses to HIV-1. The maintenance of normal $\mathrm{CD}^{+}{ }^{+} \mathrm{T}$ cell numbers and a proliferative response to HIV-1 are consistent with our previous observations in this model that infected animals do not develop immunosuppression $(1,2)$. Indeed, the ability of HIV-1-infected macaques to generate and maintain $\mathrm{CD} 4^{+} \mathrm{T}$ cell proliferative responses may be important in the observed clearance of viremia in this model.

Unlike humans, HIV-1-specific CTL were not detected directly from $M$. nemestrina PBMC. The failure to detect circulating activated CTL in fresh PBMC is similar to observations made in SIV-infected macaques (29) and HIV-1-infected chimpanzees (30). Therefore, to determine if CTL were present, we adapted methods we have previously reported to enhance detection of primed virus-specific CTL responses in cytomegalovirus-infected humans and in SIV-infected macaques $(14,20)$, and employed sequential in vitro antigen-specific stimulation with autologous cells infected with rVV containing HIV-1 genes. Using this approach, HIV-reactive CD8 ${ }^{+}$CTL was detected in bulk-stimulated PBMC cultures and HIV-1specific clones were subsequently isolated.

The demonstration of $\mathrm{CD}^{+}$cytolytic activity to HIV-1 proteins following experimental challenge with HIV-1 is consistent with the virologic evidence that HIV-1 replicates in macaques $(1,2)$. In vivo priming of $\mathrm{CD}^{+}$virus-specific CTL requires the presentation of appropriate viral peptide antigens in the context of MHC class I, and thus presumably requires HIV-1 infection of host cells. This has been most directly demonstrated in animal J90402, which was inoculated with only cell-free HIV-1. Both plasma viremia and cell-associated HIV-1 infection were present at $16 \mathrm{wk}$ after inoculation (2), and gagspecific CTL were detectable at multiple subsequent time points tested. Of note, the animal became culture negative from PBMC after week 24. The finding of CTL specific for the nef protein, which is a non-structural, regulatory gene product expressed only in infected cells, is also consistent with in vivo viral replication. The presence of virus-specific CTL responses at time points long after virus is recoverable does not define the virologic status of the host, since this finding is consistent with either long-lived $\mathrm{CD}^{+}$memory cells that can persist in the absence of replicating virus or with limited persistent viral replication in the host $(31-33)$.

We detected CTL to multiple HIV-1 proteins (env, gag, and $n e f$ ) in this animal model. CTL responses to proteins which contain conserved CTL epitopes, such as gag and nef, have been suggested to be of potential utility in HIV-1 vaccine design $(22,34)$. Additionally, studies in humans exposed to HIV-1 who did not exhibit continued viral replication demonstrated CTL responses to gag and $n e f(23,35)$, suggesting a potential role of such CTL in clearing HIV-1 infection. Our ability to detect CTL responses to gag and $n$ ef in HIV-1-inoculated $M$. nemestrina, who also clear HIV-1 viremia, supports the contention that these responses may aid in viral clearance, and the role of such responses should be directly analyzable in this animal model.

The frequency of CTLp in all our HIV-1-infected M. nemestrina was lower than that reported in persons with chronic HIV-1 infection (36-38). Using limiting dilution assays, gagspecific CTLp frequency estimates in these HIV-1-infected animals ranged from 1 per $1.34 \times 10^{5}$ to 1 per $3.8 \times 10^{5}$ cells, which were $\sim 100$-fold lower in frequency than that described in humans (37). The reduced frequency of gag-reactive CTLp from $M$. nemestrina may reflect restricted viral replication of HIV-1 within $M$. nemestrina as compared to humans. Alternatively, these differences may be in part methodologic, reflecting more efficient culture conditions for stimulating human cells. Additionally, the sites of HIV-1 replication in macaques have not been well described, and analysis of lymphocytes from other compartments, such as lymph nodes and spleens from infected animals, might reveal different CTLp frequencies.

Limited data on the kinetics of HIV-1-specific CTLp in humans with acute HIV-1 infection have suggested that cytotoxic responses to HIV-1 may play a role in controlling acute HIV-1 infection (39). Kinetic studies in humans with acute HIV-1 infection are limited, however, as it is often difficult to precisely define the time of infection, and there can be a substantial delay from the time of infection until lymphocytes from infected individuals can be examined. In HIV-1-infected macaques, CTL responses to multiple HIV-1 proteins were detected as early as $4-8 \mathrm{wk}$ after infection, suggesting a potential role of $\mathrm{CD}^{+}$responses in controlling viral replication and clearing virus as reported in humans. The definition of CTLp frequencies to various HIV-1 proteins at very early time points after acute HIV-1 infection of $M$. nemestrina may provide insights into the comparative role of specific CTL responses in initial viral clearance and the subsequent virologic course. The only alternative primate model for studying immunity to HIV1 is chimpanzees. However, very limited numbers of these primates are available for study and HIV-specific CD8 ${ }^{+}$CTL have been difficult to detect in HIV-infected chimpanzees, suggesting chimpanzees may not be as useful as macaques for studying $\mathrm{CD}^{+}$immunity $(30,40)$.

A potential causative role of $\mathrm{CD} 8^{+} \mathrm{CTL}$ in HIV-1 immunopathogenesis, by analogy with the cause of disease following a noncytopathic viral infection in mice in which virus-infected antigen-presenting cells (APCs) are lysed by CD8 ${ }^{+}$CTL, has recently been speculated by Zinkernagel and Hengartner (41). Our finding that these macaques who do not develop immunodeficiency but do develop HIV-1-specific $\mathrm{CD} 8^{+} \mathrm{CTL}$ responses suggests that persistent viral replication, rather than $\mathrm{CD} 8^{+} \mathrm{CTL}$ responses, may be a more important cause of HIV-induced immunopathology. HIV-1-specific $\mathrm{CD}^{+} \mathrm{T}$ cells with cytolytic activity have also been implicated in HIV-1 immunopathogenesis by mediating lysis of uninfected APCs or CD4 ${ }^{+}$cells (42). However, we could not detect significant HIV-1-specific CTL activity mediated by $\mathrm{CD} 4^{+}$cells in bulk cultures of macaque PBMC. Such CD4 ${ }^{+}$CTL have been reported in HIV-1 -infected humans (21), and appear to be less readily demonstrable in macaques. The use of selective depletion or adoptive transfer of $T$ cells with defined functions in this model should allow a more definitive analysis of the role of $\mathrm{CD}^{+}{ }^{+}$and $\mathrm{CD} 8^{+} \mathrm{T}$ cells in HIV-1 immunopathogenesis. 
We were able to generate a CTL clone from an HIV-1infected $M$. nemestrina that had high levels of specific lysis for HIV-1 gag proteins at low E/T ratios. Gag-reactive CTL epitopes have been well characterized in HIV-1-infected humans (34), HIV-2-infected humans (43) and SIV-infected macaques (44). A similar portion of the gag gene from SIV and HIV-1 elicit CTL responses in macaque and humans, respectively (45). This suggests that macaques may recognize a similar region of HIV-1 gag as humans, and studies to determine the epitope specificity of HIV-1-specific cellular immune responses in macaques are now possible. If similar regions are recognized, this model may prove useful for evaluating the mechanisms by which CTL select escape variants, as suggested with HIV-1-specific CTL responses (6).

In summary, this study demonstrates that HIV-1-infected $M$. nemestrina develop persistent $\mathrm{T}$ cell proliferative and cytotoxic responses to HIV-1 proteins. These animals which resist HIV-1-induced disease demonstrate persistent HIV-specific $\mathrm{CD}^{+}{ }^{+} \mathrm{T}$ cell responses in contrast to HIV-1-infected humans. The combination of HIV-1-specific $\mathrm{CD}^{+}{ }^{+}$and $\mathrm{CD} 8{ }^{+}$responses may be important in the control of replication seen in this animal, a finding which if confirmed has implications for immunity to HIV-1 infection and the design of protective vaccines.

\section{Acknowledgments}

We gratefully acknowledge the technical assistance of Anne Schmidt and help in manuscript preparation from Joanne Factor.

This work supported by National Institutes of Health grants AI27757, AI-26503, AI-05065, RR-00166, and AI-28065. S. J. Kent is a recipient of a Harkness fellowship from the Commonwealth Fund of New York and a Commonwealth AIDS research grant, Australia.

\section{References}

1. Agy, M. B., L. R. Frumkin, L. Corey, R. W. Coombs, S. M. Wolinsky, J. Koehler, W. R. Morton, and M. G. Katze. 1992. Infection of Macaca nemestrina by human immunodeficiency virus type-1. Science (Wash. DC) 257:103-106.

2. Frumkin, L. R., M. B. Agy, R. W. Coombs, L. Panther, W. R. Morton, J. Koehler, M. J. Florey, J. Dragavon, A. Schmidt, M. G. Katze et al. 1993. Acute infection of Macaca nemestrina by human immunodeficiency virus type 1. Virology. 195:422-431.

3. Ada, G. 1991. Strategies for exploiting the immune system in the design of vaccines. Mol. Immunol. 28:225-230.

4. Clerici, M., N. I. Stocks, R. A. Zajac, R. N. Boswell, D. R. Lucey, C. S. Via, and G. M. Shearer. 1989. Detection of three distinct patterns of T helper cell dysfunction in asymptomatic, human immunodeficiency virus-seropositive patients. Independence of $\mathrm{CD}^{+}$cell numbers and clinical staging. J. Clin. Invest. 84:1892-1899.

5. Walker, B. D., and F. Plata. 1990. Cytotoxic T lymphocytes against HIV. Aids (Phila.). 4:177-184

6. Phillips, R. E., S. Rowland-Jones, D. F. Nixon, F. M. Gotch, J. P. Edwards, A. O. Ogunlesi, J. G. Elvin, J. A. Rothbard, C. R. Bangham, C. R. Rizza et al 1991. Human immunodeficiency virus genetic variation that can escape cytotoxic T cell recognition. Nature (Lond.). 354:453-459.

7. Curiel, T. J., J. T. Wong, P. F. Gorczyca, R. T. Schooley, and B. D. Walker 1993. $\mathrm{CD}^{+}$human immunodeficiency virus type 1 (HIV-1) envelope-specific cytotoxic T lymphocytes derived from the peripheral blood cells of an HIV-1infected individual. Aids Res. Hum. Retroviruses. 9:61-68.

8. Gotch, F. M., R. Hovell, M. Delchambre, P. Silvera, and A. J. McMichael. 1991. Cytotoxic T-cell response to simian immunodeficiency virus by cynomolgus macaque monkeys immunized with recombinant vaccinia virus. Aids (Phila.). 5:317-320.

9. Shen, L., Z. W. Chen, M. D. Miller, V. Stallard, G. P. Mazzara, D. L. Panicali, and N. L. Letvin. 1991. Recombinant virus vaccine-induced SIV-specific $\mathrm{CD}^{+}$cytotoxic T lymphocytes. Science (Wash. DC). 252:440-443.

10. Mills, K. H., A. L. Barnard, M. Williams, M. Page, C. Ling, E. J. Stott, P. Silvera, F. Taffs, A. S. Kingsman, S. E. Adams et al. 1991. Vaccine-induced $\mathrm{CD}^{+} \mathrm{T}$ cells against the simian immunodeficiency virus gag protein. Epitope specificity and relevance to protective immunity. J. Immunol. 147:3560-3567.
11. Hu, S. L., S. G. Kosowski, and J. M. Dalrymple. 1986. Expression of AIDS virus envelope gene in recombinant vaccinia viruses. Nature (Lond.). 320:537-540.

12. Hu, S. L., B. M. Travis, J. Garrigues, J. M. Zarling, P. Sridhar, T. Dykers, J. W. Eichberg, and C. Alpers. 1990. Processing, assembly, and immunogenicity of human immunodeficiency virus core antigens expressed by recombinant vaccinia virus. Virology. 179:321-329.

13. Koenig, S., T. R. Fuerst, L. V. Wood, R. M. Woods, J. A. Suzich, G. M Jones, V. F. de-la-Cruz, R. T. Davey Jr., S. Venkatesan, B. Moss et al. 1990 Mapping the fine specificity of a cytolytic T cell response to HIV-1 nef protein. J. Immunol. 145:127-135.

14. Kent, S. J., V. Stallard, L. Corey, S.-L. Hu, W. R. Morton, L. Gritz, D. L. Panicali, and P. D. Greenberg. 1994. Analysis of CTL responses to SIV proteins in SIV infected macaques using antigen specific stimulation with recombinant vaccinia and fowlpox viruses. Aids Res. Hum. Retroviruses. 10:551-560.

15. Walker, B. D., C. Flexner, K. Birch-Limberger, L. Fisher, T. J. Paradis, A. Aldovini, R. Young, B. Moss, and R. T. Schooley. 1989. Long-term culture and fine specificity of human cytotoxic T-lymphocyte clones reactive with human immunodeficiency virus type 1. Proc. Natl. Acad. Sci. USA. 86:9514-9518.

16. Sharrock, C. E., E. Kaminski, and S. Man. 1990. Limiting dilution analysis of human T cells: a useful clinical tool. Immunol. Today. 11:281-286.

17. Taswell, C. 1981. Limiting dilution assays for the determination of immunocompetent cell frequencies. I. Data analysis. J. Immunol. 126:1614-1619.

18. Lewis, D. E., and J. V. Giorgi. 1990. Immunology of HIV infection. Int Rev. Immunol. 7:1-13

19. Clerici, M., C. S. Via, D. R. Lucey, E. Roilides, P. A. Pizzo, and G. M. Shearer. 1991. Functional dichotomy of $\mathrm{CD}^{+}{ }^{+} \mathrm{T}$ helper lymphocytes in asymptomatic human immunodeficiency virus infection. Eur. J. Immunol. 21:665-670.

20. Riddell, S. R., M. Rabin, A. P. Geballe, W. J. Britt, and P. D. Greenberg 1991. Class I MHC-restricted cytotoxic T lymphocyte recognition of cells infected with human cytomegalovirus does not require endogenous viral gene expression. J. Immunol. 146:2795-804.

21. Kundu, S. K., and T. C. Merigan. 1992. Equivalent recognition of HIV proteins, env, gag and pol, by $\mathrm{CD}^{+}{ }^{+}$and $\mathrm{CD}^{+}$cytotoxic T-lymphocytes. Aids (Phila.). 6:643-649.

22. Hadida, F., A. Parrot, M.-P. Kieny, B. Sadat-Sowti, C. Mayaud, P. Debre and B. Autran. 1992. Carboxyl-terminal and central regions of human immunodeficiency virus-1 Nef recognized by cytotoxic T lymphocytes from lymphoid organs. An in vitro limiting dilution analysis. J. Clin. Invest. 89:53-60.

23. Langlade-Demoyen, P., N. Ngo-Giang-Huong, F. Ferchal, and E. Oksenhendler. 1994. Human immunodeficiency virus (HIV) nef-specific cytotoxic T lymphocytes in noninfected heterosexual contact of HIV-infected patients. J. Clin. Invest. 93:1293-1297.

24. Hu, S. L., B. M. Travis, V. Stallard, K. Abrams, L. Misher, P. Moran, J. M. Zarling, A. J. Langlois, L. Kuller, W. R. Morton et al. 1992. Immune responses to SIVmne envelope glycoproteins protect macaques from homologous SIV infection. Aids Res. Hum. Retroviruses. 8:1489-1494.

25. Cooney, E. L., M. J. McElrath, L. Corey, S. L. Hu, A. C. Collier, D. Arditti, M. Hoffman, R. W. Coombs, G. E. Smith, and P. D. Greenberg. 1993 Enhanced immunity to human immunodeficiency virus (HIV) envelope elicited by a combined vaccine regimen consisting of priming with a vaccinia recombinan expressing HIV envelope and boosting with gp160 protein. Proc. Natl. Acad. Sci. USA. 90:1882-1886.

26. Van-Eendenburg, J. P., M. Yagello, M. Girard, M. P. Kieny, J. P. Lecocq, E. Muchmore, P. N. Fultz, Y. Riviere, L. Montagnier, and J. C. Gluckman. 1989. Cell-mediated immune proliferative responses to HIV-1 of chimpanzees vaccinated with different vaccinia recombinant viruses. Aids Res. Hum. Retroviruses. 5:41-50.

27. Gray, D., and P. Matzinger. 1991. T cell memory is short-lived in the absence of antigen. J. Exp. Med. 174:969-974.

28. Cooney, E. L., A. C. Collier, P. D. Greenberg, R. W. Coombs, J. Zarling, D. E. Arditti, M. C. Hoffman, S. L. Hu, and L. Corey. 1991. Safety of and immunological response to a recombinant vaccinia virus vaccine expressing HIV envelope glycoprotein [see comments]. Lancet. 337:567-572.

29. Miller, M. D., C. I. Lord, V. Stallard, G. P. Mazzara, and N. L. Letvin 1990. The gag-specific cytotoxic T lymphocytes in rhesus monkeys infected with the simian immunodeficiency virus of macaques. J. Immunol. 144:122-128.

30. Ferrari, G., J. Ottinger, C. Place, S. M. Nigida, Jr., L. O. Arthur, and K. J. Weinhold. 1993. The impact of HIV-1 infection on phenotypic and functional parameters of cellular immunity in chimpanzees. Aids Res. Hum. Retroviruses. 9:647-656.

31. Oehen, S., H. Waldner, T. M. Kundig, H. Hengartner, and R. M. Zinkernagel. 1992. Antivirally protective cytotoxic T cell memory to lymphocytic choriomeningitis virus is governed by persisting antigen. J. Exp. Med. 176:1273-1281

32. Jamieson, B. D., and R. Ahmed. 1989. T cell memory. Long-term persistence of virus-specific cytotoxic T cells. J. Exp. Med. 169:1993-2005.

33. Lau, L. L., B. D. Jamieson, T. Somasundaram, and R. Ahmed. 1994 Cytotoxic T-cell memory without antigen. Nature (Lond.). 369:648-652.

34. Johnson, R. P., A. Trocha, L. Yang, G. P. Mazzara, D. L. Panicali, T. M Buchanan, and B. D. Walker. 1991. HIV-1 gag-specific cytotoxic T lymphocytes 
recognize multiple highly conserved epitopes. Fine specificity of the gag-specific response defined by using unstimulated peripheral blood mononuclear cells and cloned effector cells. J. Immunol. 147:1512-1521.

35. Rowland-Jones, S. L., D. F. Nixon, M. C. Aldhous, F. Gotch, K. Ariyoshi, N. Hallam, J. S. Kroll, K. Froebel, and A. McMichael. 1993. HIV-specific cytotoxic T-cell activity in an HIV-exposed but uninfected infant. Lancet. 341:860861 .

36. Lamhamedi-Cherradi, S., B. Culmann-Penciolelli, B. Guy, M. P. Ki'eny, F. Dreyfus, A. G. Saimot, D. Sereni, D. Sicard, J. P. L'evy, and E. Gomard. 1992. Qualitative and quantitative analysis of human cytotoxic T-lymphocyte responses to HIV-1 proteins. Aids (Phila.). 6:1249-1258.

37. Hoffenbach, A., P. Langlade-Demoyen, G. Dadaglio, E. Vilmer, F. Michel, C. Mayaud, B. Autran, and F. Plata. 1989. Unusually high frequencies of HIV specific cytotoxic T lymphocytes in humans. J. Immunol. 142:452-462.

38. Koup, R. A., C. A. Pikora, K. Luzuriaga, D. B. Brettler, E. S. Day, G. P. Mazzara, and J. L. Sullivan. 1991. Limiting dilution analysis of cytotoxic lymphocytes to human immunodeficiency virus gag antigens in infected persons: in vitro quantitation of effector cell populations with p17 and p24 specificities J. Exp. Med. 174:1593-600.

39. Koup, R. A., J. T. Safrit, Y. Cao, C. A. Andrews, G. McLeod, W. Borkowshy, C. Farthing, and D. D. Ho. 1994. Temporal association of cellular immune responses with the initial control of viremia in primary human immunodeficiency virus type 1 syndrome. J. Virol. 68:4650-4655.
40. Zarling, J. M., J. A. Ledbetter, J. Sias, P. Fultz, J. Eichberg, G. Gjerset, and P. A. Moran. 1990. HIV-infected humans, but not chimpanzees, have circulating cytotoxic T lymphocytes that lyse uninfected CD4 ${ }^{+}$cells. J. Immunol. 144:29922998

41. Zinkernagel, R. M., and H. Hengartner. 1994. T-cell-mediated immunopathology versus direct cytolysis by virus: implications for HIV and AIDS. Immunol. Today. 15:262-268.

42. Orentas, R. J., J. E. Hildreth, E. Obah, M. Polydef kis, G. E. Smith, M. L. Clements, and R. F. Siliciano. 1990. Induction of CD4 ${ }^{+}$human cytolytic T cells specific for HIV-infected cells by a gp160 subunit vaccine. Science (Wash. DC). 248:1234-1237.

43. Gotch, F., S. N. McAdam, C. E. Allsopp, A. Gallimore, J. Elvin, M. P. Kieny, A. V. Hill, A. J. McMichael, and H. C. Whittle. 1993. Cytotoxic T cells in HIV2 seropositive Gambians. Identification of a virus-specific MHC-restricted peptide epitope. J. Immunol. 151:3361-3369.

44. Yamamoto, H., M. D. Miller, H. Tsubota, D. I. Watkins, G. P. Mazzara, V. Stallard, D. L. Panicali, A. Aldovini, R. A. Young, and N. L. Letvin. 1990. Studies of cloned simian immunodeficiency virus-specific T lymphocytes. gagspecific cytotoxic T lymphocytes exhibit a restricted epitope specificity. J. Immunol. 144:3385-3391.

45. Buseyne, F., M. McChesney, F. Porrot, S. Kovarik, B. Guy, and Y. Riviere. 1993. Gag-specific cytotoxic T lymphocytes from human immunodeficiency virus type 1-infected individuals: gag epitopes are clustered in three regions of the p24 gag protein. J. Virol. 67:694-702. 